\title{
Аналіз зміни середньооб'ємної температури при охолодженні харчових продуктів
}

\author{
О.С. Подмазко, І.О. Подмазко
}

Одеська національна академія харчових технологій, вул. Канатна,112, м. Одеса, 65039, Україна

\begin{abstract}
В роботі розглянуто змінення середньооб'ємної температури продукту (на прикладі м'яса) при його охолодженні. Використані різноманітні методи розрахунків. Розглянута можливість продукту віддати теплоту та можливість охолоджувального середовища сприйняти ињю теплоту.
\end{abstract}

Ключові слова: Охолодження; Середньооб'ємна температура тіла; Температурне поле продукту; Критерї Фур'є $\epsilon$, Бio

(C) The Author(s) 2018. This article is an open access publication

This work is licensed under the Creative Commons Attribution 4.0 International License (CC BY) http://creativecommons.org/licenses/by/4.0/

\section{1. Вступ}

Охолодження - це процес відведення теплоти від харчових продуктів 3 пониженням їх температури не нижче кріоскопічної температури. При аналізі процесів термообробки продуктів необхідно враховувати наступі фактори:

- можливість продукту віддати теплоту;

- можливість охолоджувального середовища сприйняти цю теплоту;

- можливість приборів охолодження відвести цю теплоту.

В період охолодження спостерігається: коливання температур охолоджувального середовища, кипіння холодильного агенту, теплового навантаження на прибори охолодження, компресор, конденсатор і т.п. [1, 2].

Як правило, охолодження продуктів - це не стаціонарний процес і для його розрахунку використовують аналітичні залежності або номограми для різних форм тіла (пластини, циліндри, кулі).

\section{2. Методи розрахунку теплового потоку від продукту}

При підборі холодильного обладнання необхідно знати кількість теплоти (або теплового потоку), яка відводиться від продукту при його охолодженні. Це завдання можна вирішити, використовуючи три підходи.

Перший підхід заснований на законі Фур'є і зводиться до визначення кількості теплоти, що передається теплопровідністю від внутрішніх шарів до зовнішньої поверхні. По суті, це внутрішня задача теплообміну. Щільність теплового потоку (внутрішнього) розраховують по формулі:

$$
q=\frac{\lambda}{\delta} \cdot\left(t_{\mathrm{m}}-t_{\mathrm{n}}\right)
$$

де $\lambda$ - коефіцієнт теплопровідності продукту, Вт/(м·К); $\delta$ - половина визначального розміру продукту, м; $t_{u}, t_{n}-$ температури, відповідно, центру і поверхні продукту, ${ }^{\circ} \mathrm{C}$.

Другий підхід заснований на законі НьютонаРіхмана і зводиться до визначення кількості теплоти, що передається від поверхні тіла до навколишнього середовища. По суті, це зовнішня задача (гранична умова третього роду).

$$
Q=\alpha \cdot F \cdot\left(t_{\mathrm{n}}-t_{\mathrm{c}}\right)
$$

де $\alpha$ - коефіцієнт тепловіддачі від поверхні продукту до охолоджуючого середовища, Вт/( $\left.{ }^{2} \cdot \mathrm{K}\right)$;

$F$ - площа поверхні продукту, Вт/м²;

$t_{c}$ - температура температура охолоджувального середовища, ${ }^{\circ} \mathrm{C}$.

Третій підхід заснований на урахуванні питомої теплоємності продукту, маси, а також на зміні його середньооб'ємної температури:

або

$$
Q=G \cdot C \cdot\left(t_{\text {ขпоч }}-t_{\text {ขкін }}\right)
$$

$$
Q=G \cdot\left(i_{\text {поч }}-i_{\text {кін }}\right)
$$

де $Q$ - загальна кількість теплоти, кДж;

$t_{\text {vnоч }}$ - початкова середньооб'ємна температура, ${ }^{\circ} \mathrm{C}$;

$t_{\text {vкін }}-$ кінцева середньооб'ємна температура, ${ }^{\circ} \mathrm{C}$;

$G$ - маса продукту, кг;

$C$ - питома теплоємність продукту, кДж/(кг·К);

$i_{\text {поч }}, i_{\text {кін }}$ відповідна, початкова і кінцева ентальпія продукту, кДж/кг.

Як правило, при розрахунках процесів холодильної обробки використовують третій шлях, тобто ведуть розрахунок по масі, питомій теплоємкості і різниці середньооб'ємних температур.

У разі процесів в холодильній обробці можна розглядати одномірне температурне поле $t=f(x, t)$. Температурне поле продукту залежить від розміру, конфігурації і теплофізичних властивостей об'єкта, від умов відведення теплоти.

В аналізі теплофізичних процесів холодильної технології і відповідних теплових розрахунках дуже потрібною величиною є середньооб'ємна температура тіла: 


$$
t_{v}=t_{\mathrm{L}}-\Psi \cdot\left(t_{\mathrm{u}}-t_{\mathrm{n}}\right)
$$

де $\Psi$ - коефіцієнт, який визначається формою тіла.

Нижче наведені значення для різних форм тіла i умов охолодження:

Таблиця 1 - Значення $\Psi$ для різних форм тіла і умов охолодження

\begin{tabular}{|c|c|c|}
\hline Форма тіла & $\begin{array}{c}\text { Охолодження в } \\
\text { повітрі }\end{array}$ & $\begin{array}{c}\text { Охолодження в } \\
\text { рідині }\end{array}$ \\
\hline Пластина & $1 / 3$ & $1 / 4$ \\
\hline Циліндр & $1 / 2$ & $2 / 5$ \\
\hline Куля & $3 / 5$ & $1 / 2$ \\
\hline
\end{tabular}

Однак, використання рівняння (5) не завжди зручно, тому що необхідно знати температуру поверхні продукту $t_{n}$, що відповідає граничним умовам першого роду. При граничних умовах третього роду, коли відомі температура середовища $t_{c}$ і коефіцієнт тепловіддачі $\alpha$ :

$$
t_{v}=t_{\text {ч }}-\frac{B i}{B i+n} \cdot \Psi \cdot\left(t_{\text {ч }}-t_{\mathrm{c}}\right)
$$

де $B i=\alpha \cdot \frac{\delta}{\pi}-$ критерий Біо;

При повітряному охолодженні $n=2$, при охолодженні в рідині $n=3$.

Для рішення задач, пов'язаних з нестаціонарним теплообміном як в аналітичному вигляді, так і за допомогою номограм користуються наступними величинами:

- безрозмірним температурним комплексом:

$$
\theta=\frac{t(x, \tau)-t_{c}}{t_{\text {noч }}-t_{c}}
$$

де $t(x, \tau)$ - поточна температура, ${ }^{\circ} \mathrm{C}$; ${ }^{\circ} \mathrm{C}$;

$t_{c}$ - температура охолоджувального середовища,

$t_{\text {nоч }}-$ початкова температура продукту, ${ }^{\circ} \mathrm{C}$.

- критерієм Фур'є:

$$
F o=\frac{a \cdot \tau}{R^{2}}
$$

де $a=\lambda /(C \cdot \rho)$ - коефіцієнт температуропровідності, $\mathrm{M}^{2} / \mathrm{c}$;

$\rho$ - питома щільність продукту, кг/м ${ }^{3}$;

$\tau-$ час охолодження, с;

$R=\delta / 2-$ визначальний розмір, м.

- та критерієм Біо.

Для аналітичних розрахунків середньооб'ємної температури продукту на основі теорії академіка О.В. Ликова професор М.О. Головкін [3] запропонував формулу безрозмірного температурного комплексу (при значеннях критерія Фур'є менше одиниці), в якій відсутній критерій Біо:

$$
\bar{\theta}=\frac{\bar{t}-t_{c}}{t_{\text {nоч }}-t_{c}}=\frac{8}{\pi^{2}} \cdot e^{-\frac{\pi^{2} \cdot F_{0}}{4}}
$$

де $\bar{t}$ - середньооб'ємна температура продукту, ${ }^{\circ} \mathrm{C}$.

\section{3. Розрахунок теплових потоків від продукту}

Для подальших розрахунків візьмемо м'ясну пластину $R=0,2$ м; теплоємність $C=2,8$ кДж/(кг·К); коефіцієнт теплопровідності $\lambda=0,4 \mathrm{BT} /\left(\right.$ м.К), при $F=1 \mathrm{~m}^{2}$ маса продукту $G=100$ кг; початкова температура продукту $t_{\text {поч }}=40^{\circ} \mathrm{C}$.

Використовуючи формулу (9), були проведені розрахунки середньо об'ємної температури при різних температурах охолоджувального повітря $t_{c}$. Результати представлені на рис. 1.

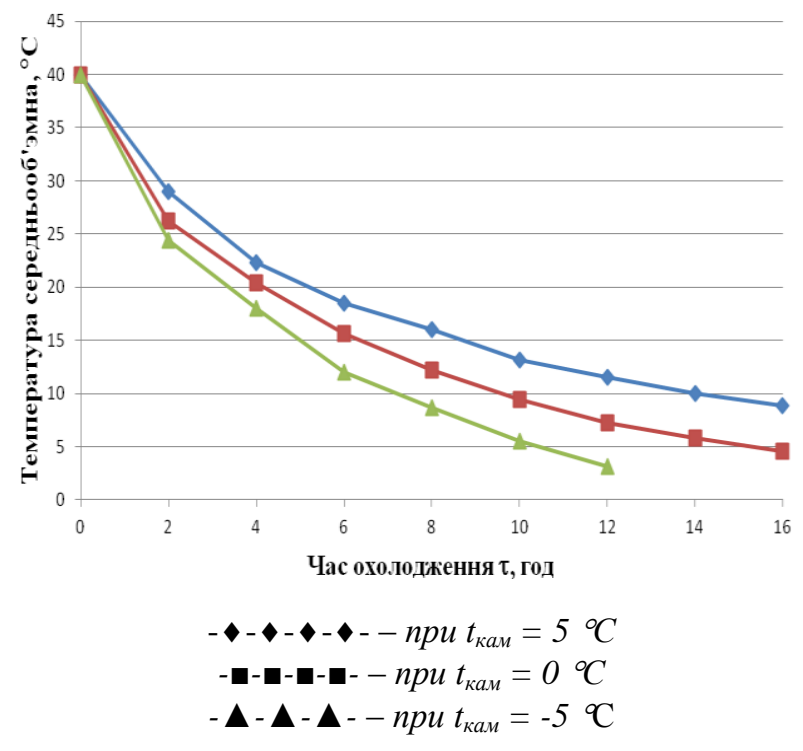

Рисунок 1 - Залежність середнєоб'ємної температури

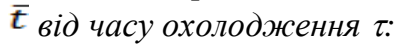

Розглянемо граничний випадок, коли температура поверхні продукту становиться рівною температурі охолоджувального середовища з самого початку охолодження (контактний спосіб). В цьому випадку

можливість охолоджувального середовища відвести теплоту від продукту не обмежена. Використовуючи формулу (6), відносно температури центру $t_{u}$, були отримані наступні результати, представлені на рис. 2 .

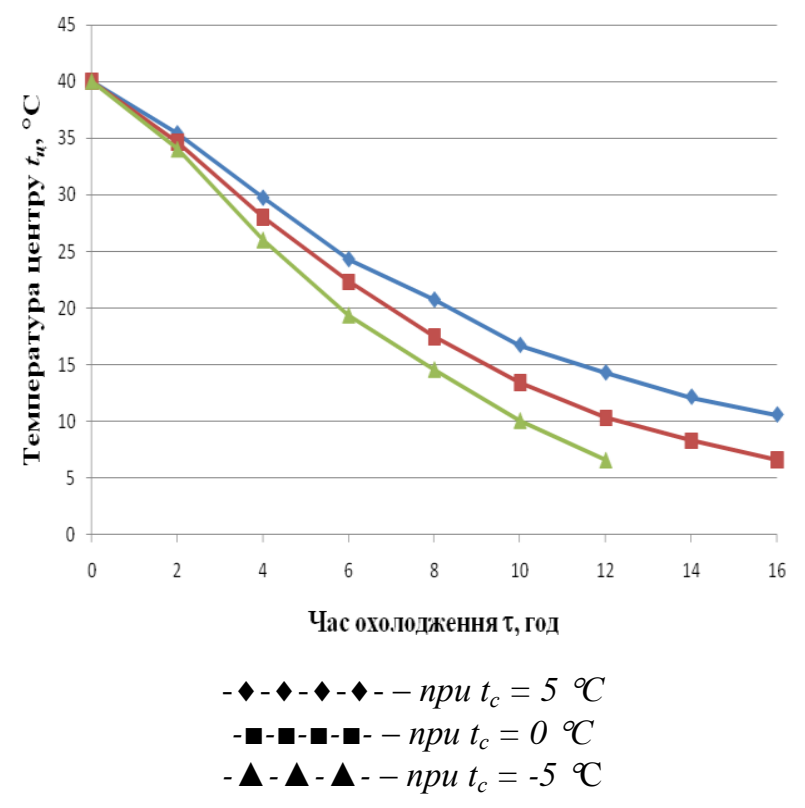

Рисунок 2 - Залежність температури цеентру $t_{u}$ від часу охолодження $\tau$ :

Використовуючи дані, представлені на рис. 1 та рис. 2 , були проведені розрахунки теплового потоку від 
продукту при його охолодженні по середньооб'ємній температурі продукту та температурі центру. Результати представлені, відповідно, на рис. 3 і рис. 4.

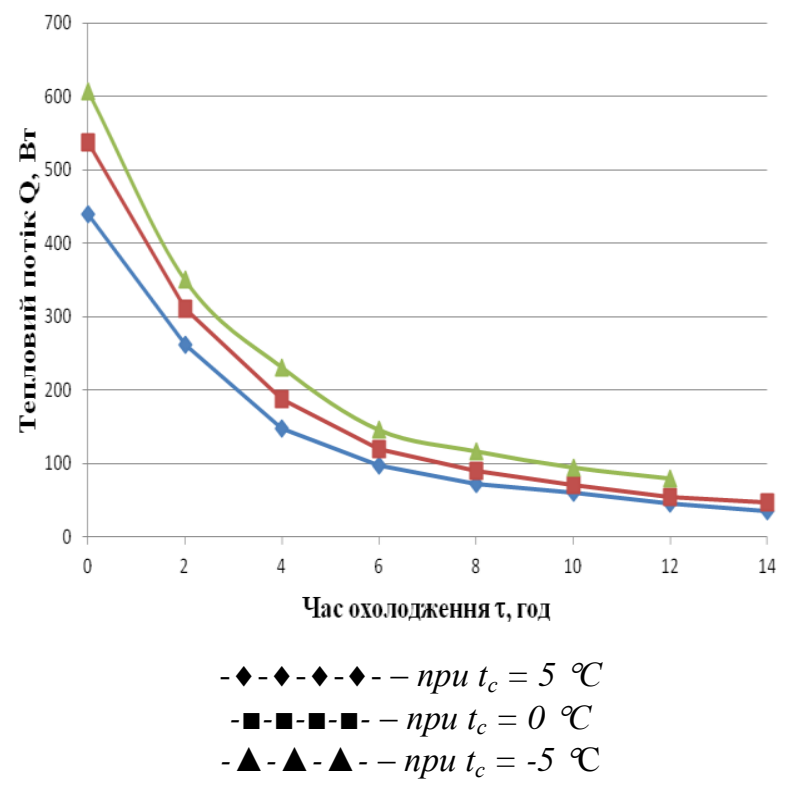

Рисунок 3 - Динаміка зміни теплового потоку від часу охолодження $\tau$ :

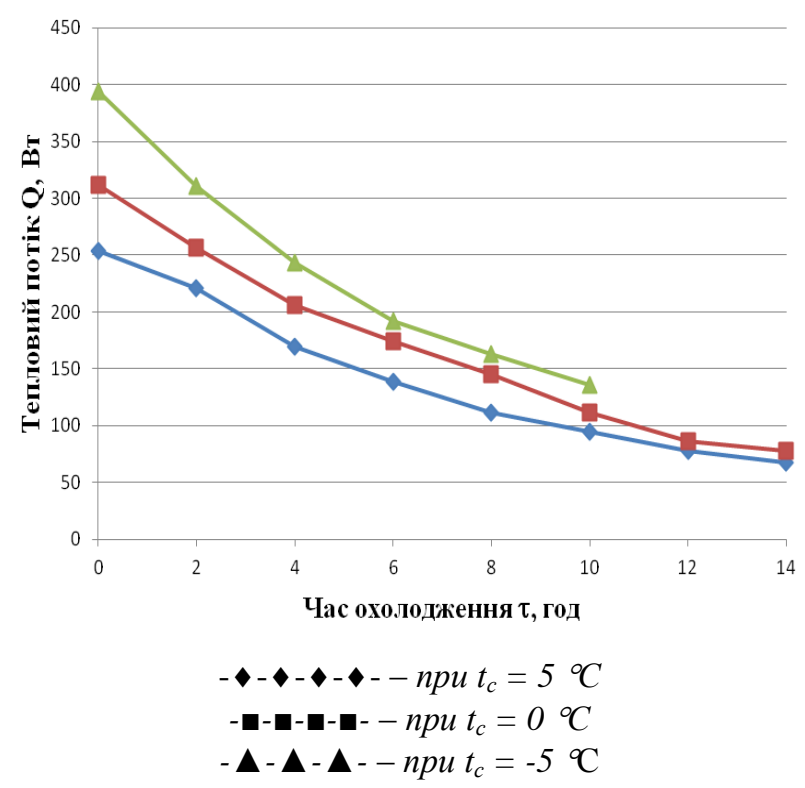

Рисунок 4 - Динаміка зміни теплового потоку від часу охолодження $\tau$ :

Слід зазначити, що температура поверхні продукту стає рівною температурі охолоджувального середовища $з$ самого початку охолодження - це практично не можливо навіть в контактних апаратах. Зазначимо також, що охолодження продуктів, як правило, проводиться в повітряному середовищі. Проведемо розрахунок температури поверхні продукту, скориставшись формулою (2), та даними, представленими на рис. 3 . Приймемо максимально можливий коефіцієнт тепловіддачі від поверхні продукту до охолоджуючого середовища $\alpha=20 \mathrm{BT} /\left(\mathrm{M}^{2} \cdot \mathrm{K}\right)$.

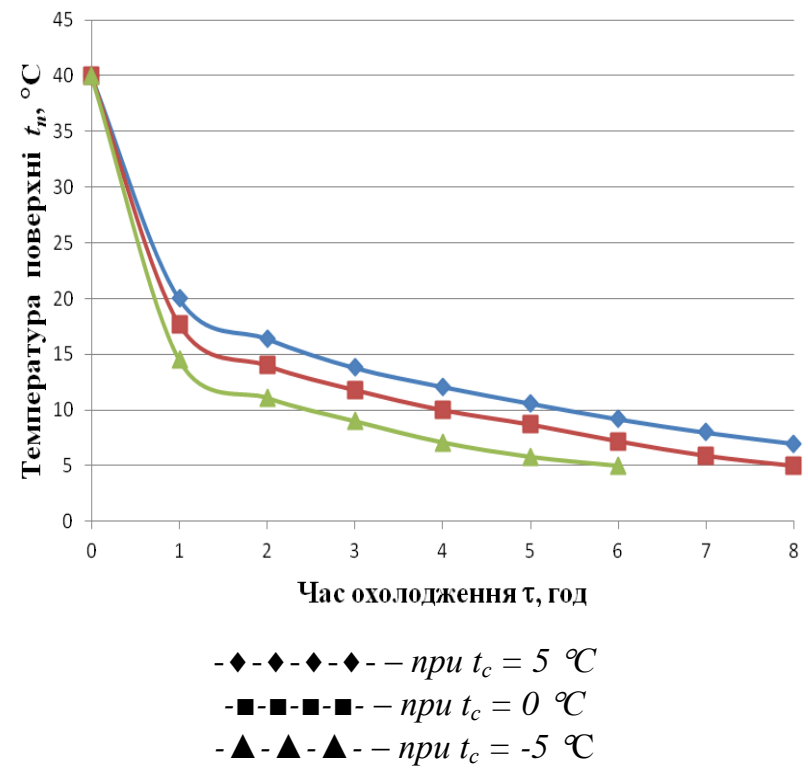

Рисунок 5 - Залежність температури поверхні $t_{n}$ від часу охолодження $\tau$ :

Як видно із отриманих даних, температура поверхні продукту також змінюється по експоненціальній залежності, та далеко не одразу становиться рівною температурі охолоджувального повітря.

\section{4. Висновки}

Для аналітичних розрахунків температур продукту: середньооб'ємної, поверхні та центру в формулах необхідно враховувати не тільки критерій Фур'є (внутрішня задача), але і критерій Біо (зовнішня). Так, як це робиться при використанні номограм (діаграм). Трактування, що при значеннях критерія Фур'є менше одиниці можливість продукту віддати теплоту значно менша (пояснюється низьким коефіцієнтом температуропровідності, що характерно для будь-якого продукту), ніж можливість охолоджувального середовища сприйняти цю теплоту - не завжди вірна. При повітряному охолоджені значення теплофізичних характеристик повітря також не високі, тому і спостерігається підвищення температури в камері в початковий момент часу $[1,2]$. Слід також враховувати, що камерне обладнання підбирається по середньому тепловому навантажені, i його спроможність відвести теплоту від повітря не достатня в початковий період охолодження продукту.

\section{Література}

1. Подмазко А.С. Исследование параметров холодильной установки при переменных тепловых нагрузках / А.С. Подмазко // Холодильная техника и технология - ОГАХ, 2002, № 3. - с. $22-27$.

2. Подмазко А.С. Моделирование процессов работы охлаждающей системы при нестационарных тепловых режимах / А.С. Подмазко // Холодильная техника и технология - ОГАХ, 2003, № 2. - с. 5-11.

3. Головкин Н.А. Холодильная технология пищевых продуктов / Н.А. Головкин // М.: Легкая и пищевая промышленность. - 1984. - 239 с. 


\section{Analysis of changes in mean volume temperature during cooling of food products}

\section{O. Podmazko, I. Podmazko}

Odessa National Academy of Food Technologies, 112 Kanatnaia str., Odessa, 65039, Ukraine

The change in average volume temperature of the product (on the example of meat) when it is cooled is considered in the paper. Various calculation methods are used. An important value when calculating the amount of heat (heat flux) released from the product when it is cooled is the average volume of temperature. The easiest way to determine it is to measure an average of the arithmetic mean of surface temperature and product center. There is also a series of formulas - analytic, empirical for its definition. For analytical calculations of product temperatures: the average volume temperature, the surface temperature and the center temperature, it is necessary to take into consideration in the formulas not only the Fourier criterion (internal problem), but also the criterion Bio (external). It is not always correct that in case when the values of the Fourier criterion are less than one, the possibility of a product to give off heat is lower (due to the low coefficient of temperature conductivity that is characteristic of any product) than the ability of the cooling medium to accept this heat. In the conditions of air cooling the values of the thermophysical characteristics of the air are also not high, that's why the increase in the temperature in the chamber at the initial moment of time is observed [1, 2]. It should also be taken into account that the chamber equipment is selected according to the average thermal load, and its ability to remove heat from the air is not sufficient in the initial period of the product cooling.

Keywords: Cooling; Temperature Of Medium Volume; Temperature Field Of Food; Criterion Of Fourier, Bio.

\section{References}

1. Podmazko A. Issledovanie parametrov holodil'noj ustanovki pri peremennyh teplovyh nagruzkah / A. Podmazko // Holodil'naya tekhnika i tekhnologiya ОГАХ OGAH, 2002, № 3 - 22 - 27 (in Russian)

2. Podmazko A. Modelirovanie processov raboty ohlazhdayushchej sistemy pri nestacionarnyh teplovyh rezhimah / A. Podmazko // Holodil'naya tekhnika i tekhnologiya ОГАХ - OGAH, 2003, № 2 - 5 - 11 (in Russian)

3. Golovkin N. Holodil'naya tekhnologiya pishchevyh produktov / N. Golovkin // M.: Legkaya i pishchevaya promyshlennost'. - 1984. - 239 (in Russian) 